\title{
Full Volumetric 3-D Vector Flow Imaging Using a 62+62 Row-Column Array
}

Schou, Mikkel; Jørgensen, Lasse Thurmann; Stuart, Matthias Bo; Traberg, Marie Sand; Tomov, Borislav Gueorguiev; Jensen, Jørgen Arendt

\section{Published in:}

Proceedings of 2019 IEEE International Ultrasonics Symposium

Link to article, DOI:

10.1109/ULTSYM.2019.8925885

Publication date:

2019

Document Version

Peer reviewed version

Link back to DTU Orbit

Citation (APA):

Schou, M., Jørgensen, L. T., Stuart, M. B., Traberg, M. S., Tomov, B. G., \& Jensen, J. A. (2019). Full Volumetric 3-D Vector Flow Imaging Using a 62+62 Row-Column Array. In Proceedings of 2019 IEEE International Ultrasonics Symposium (pp. 864-867). IEEE. https://doi.org/10.1109/ULTSYM.2019.8925885

\section{General rights}

Copyright and moral rights for the publications made accessible in the public portal are retained by the authors and/or other copyright owners and it is a condition of accessing publications that users recognise and abide by the legal requirements associated with these rights.

- Users may download and print one copy of any publication from the public portal for the purpose of private study or research.

- You may not further distribute the material or use it for any profit-making activity or commercial gain

- You may freely distribute the URL identifying the publication in the public portal 


\title{
Full Volumetric 3-D Vector Flow Imaging using a 62+62 Row-Column Array
}

\author{
Mikkel Schou, Lasse Thurmann Jørgensen, Matthias Bo Stuart, \\ Marie Sand Traberg, Borislav Gueorguiev Tomov and Jørgen Arendt Jensen. \\ Center for Fast Ultrasound Imaging, Department of Health Technology, \\ Technical University of Denmark, DK-2800 Lyngby, Denmark
}

\begin{abstract}
Row Column (RC) Arrays can produce highresolution 3-D volumetric images with only $2 \mathrm{~N}$ interconnections compared to $\mathrm{N}^{2}$ for matrix probes. A $62+62 \mathrm{RC}$ probe has four times larger surface area and one-eighth of the channel count when compared to the same-pitch fully populated $32 \times 32$ matrix probe. This research investigates the performance of such a prototype array for volumetric Synthetic Aperture (SA) B-mode and vector flow imaging using defocused waves. An interleaved SA sequence was implemented on the SARUS scanner using a $3 \mathrm{MHz}, \lambda / 2$-pitch $62+62 \mathrm{RC}$ piezoelectric probe. The sequence contains repeated emissions with rows and columns interleaved with B-mode emissions. The sequence contains 80 emissions in total and can provide a volume rate above $125 \mathrm{~Hz}$ yielding continuous data. Velocities were estimated using the Directional Transverse Oscillation Cross-Correlation method. Measurements were made on a circulating flow rig with a parabolic profile with a peak velocity of $0.25 \mathrm{~m} / \mathrm{s}$ and beam-to-flow angle of $90^{\circ}$, and two different rotation angles $\left(0^{\circ}, 4^{\circ}\right)$. Results showed a maximum bias of $\mathbf{- 1 7 . 5 \%}$ and a standard deviation of $3.9 \%$. A second setup used a tissue mimicking phantom with pulsating flow showing full volumetric flow estimated using the method. The flow was visualized in the entire rectilinear volume at once, with B-mode planes selectable in the entire region. This was attained using only 62 channels in receive making full volumetric imaging and velocity estimation implementable on current scanner hardware.
\end{abstract}

\section{INTRODUCTION}

Crossed electrode arrays introduced by Morton and Lockwood [1], later called row-column (RC) arrays [2]-[5] have shown potential for 3-D imaging, as it greatly reduces the number of channels compared to fully addressed matrix arrays [6]. The number of channels scales linearly with the side length. Having 62+62 channels results in a surface area of (62 $\times$ pitch $)^{2}$ for the RC array. To cover the same area using a fully addressed matrix array would necessitate $62^{2}=3844$ channels, making it difficult to implement in terms of hardware and beamforming. RC addressing is therefore ideal when a larger surface area is required. It translates to better performance in terms of resolution and contrast and provides higher pressure compared to a sparsely addressed array. This makes the RC array ideal for flow imaging without the aid of contrast agents.

Flow imaging has previously been attained using an $\mathrm{RC}$ setup. Holbek et al. [7] presented a method of estimating the 3 -D velocity components in a plane using repeated steered emissions. The velocity was estimated using the Transverse Oscillation (TO) method [7], [8]. Repeated emissions and steering across the volume then revealed a volumetric 3-
D vector flow image. The method was precise but had an issue with low frame rate; a result of the high number of transmissions used to cover the entire volume [9]. Sauvage et al. [10] employed a large $128+128$ elements RC array with plane wave emissions, but revealed grating lobes at an unacceptable level of $-5 \mathrm{~dB}$, due to the employment of a $\lambda$ pitch RC array. In this work the full volumetric 3-D vector flow can be estimated using a flat-surfaced $62+62 \mathrm{RC}$ addressed array employing a Synthetic Aperture (SA) imaging sequence utilizing interleaved emissions [11]-[13] to mitigate frame rate issues. This sequence allows for the full 3-D volumetric flow to be estimated using only 62 channels in receive.

\section{Methods}

\section{A. Imaging Sequence and Beamforming}

A $62+62$ RC piezoelectric experimental probe [14] was connected to the research scanner SARUS [15]. This allowed full control over emissions and storing of all channel data. Using SA, each emission can be beamformed to reveal a low resolution volume (LRV). A single LRV will reveal a volume only focused in receive. However, summing multiple LRVs with changing transmit geometries (virtual line sources) will reveal a high resolution volume (HRV) [16]. HRVs are then focused dynamically both in receive and synthetically in transmit. The SA sequence used here interleaves the flow emissions inside a flow block, and it also interleaves Bmode emissions between flow blocks. The sequence uses a combination of row emissions $(R)$ and column emissions $(C)$ suited for flow estimation, see section II-B for details.

B-mode requires a higher number and more widespread virtual lines sources to avoid grating lobes and limit the sidelobe energy to improve contrast. The B-mode emissions were therefore interleaved, with 4 emissions per block, in between flow blocks in the following pattern:

\begin{tabular}{|l|l|l|l|}
\hline$R(16)$ & $B_{R}(4)$ & $C(16)$ & $B_{R}(4)$ \\
\hline$R(16)$ & $B_{R}(4)$ & $C(16)$ & $B_{R}(4)$ \\
\hline
\end{tabular}

Here $B_{R}$ indicates that the emissions are used for B-mode and that the emissions are performed with rows. The number in parentheses correspond to the number of emissions in each block. $R$ and $C$ symbolize flow blocks. $R$ have rows as transmitting elements and columns elements are receiving. $C$ is the flipped setup, having columns as transmitting elements 

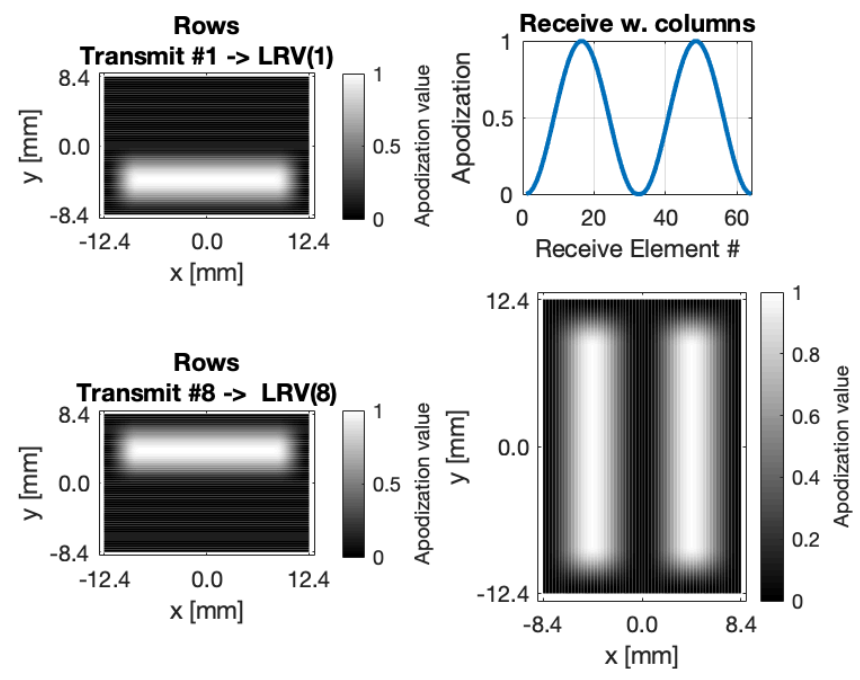

Fig. 1. Transmit setup using the rows. Visualizing the transmit apodization on the left panel for two different emissions. The receive apodization is shown to the right. Notice how the apodization is the same across the entire length of the direction.

and rows as receivers. This way, only 62 channels have to be active in receive per emission. This reduces the bandwidth, data handling, and hardware requirement.

TABLE I

PROBE PARAMETERS AND IMAGING SETTINGS

\begin{tabular}{l|l}
\multicolumn{2}{c}{ Probe dimensions } \\
\hline Number of elements & $62+62$ \\
Center frequency: & $3 \mathrm{MHz}$ \\
Kerf & $25 \mu \mathrm{m}$ \\
Pitch & $0.27 \mathrm{~mm}$ \\
Element length & $19 \mathrm{~mm}$ \\
Total Surface area & $280.23 \mathrm{~mm}^{2}$ \\
\hline \multicolumn{2}{c}{ Imaging Parameters } \\
\hline Transmit Apodization & Hann \\
F\# (TX/RCV) & $-1 / 1$ \\
Number of active elements & 32 \\
No. transmitted cycles & 2 \\
Transmit frequency & $3 \mathrm{MHz}$ \\
$f_{\text {prf }}$ & $2 \mathrm{kHz}$ \\
\hline
\end{tabular}

A single flow block, here using $R$ as an example, generated a total of two HRVs $\left(H R V_{a}, H R V_{b}\right)$. Each HRV is synthesized from eight LRVs, with different transmit virtual line sources. The emissions were defocused to ensure high spatial overlap of the emitted waves in front of the transducer. This was employed by placing the virtual line sources behind the transducer. A sliding aperture approach using 32 active elements with an F\# of -1 was used in transmit, and the full 62 orthogonal elements in receive. This is visualized in Fig. 1, with transmit event number 1 and 8. Repeating each emission once generated a second pair of LRVs, which was used to generate a second HRV. The emissions in a single flow block were interleaved as:

$$
R: \quad L R V_{a}(1)\left|L R V_{b}(1)\right| \ldots\left|L R V_{a}(8)\right| L R V_{b}(8)
$$

The first set of emissions has subscript $a$, and the repeated emission has $b$. Two consecutive emissions are identical. This interleaving ensures a temporal separation between $H R V_{a}$ and $H R V_{b}$ only limited by the pulse repetition frequency $\left(f_{p r f}\right)$. The volumetric B-mode is comprised of 24 different LRVs, where eight are reused from the two $R$ from the full sequence in (1). The total number of emissions was 80 , providing a B-mode volume rate of $1 / 80 \cdot f_{p r f}$. The parameters for the imaging sequence and probe dimensions are found in Table I.

For each emission, the data was stored and beamformed offline using a specialized delay and sum beamformer [5] to form the LRVs. The beamformer was implemented on a GPU in MATLAB (MathWorks) [17]. The HRVs were generated using:

$$
H R V(x, y, z)=\sum_{i=1}^{N} W(x, y, z, i) \cdot \operatorname{LRV}(x, y, z, i) .
$$

Here $N$ is the number of LRVs, $W$ is a weighting matrix that employs a dynamically expanding aperture, with a synthetic F-number of 1 . This allowed full control over apodization in receive, a crucial step in the TO velocity estimation method.

\section{B. Velocity Estimation}

The TO method requires an oscillating field in the transverse direction to estimate the velocity component parallel to the transducer surface. This was employed using a dual peak apodization in receive as visualized in Fig. 1. The field will only be oscillating in one direction e.g. in $x$, in this case. This is why only $v_{x}$ can be estimated when rows are emitting. $v_{y}$ is estimated using block $C$. $v_{z}$ can be estimated in either case due to the natural oscillation of the propagating wave. Velocities were estimated using Directional Transverse Oscillation (DTO) [18]. Interleaving flow emissions have already shown to provide higher detectable velocities and better performance in 2-D SA flow estimation [12], [13]. The approach is not limited to 2-D and can be employed on a full volume at once and provide full 3-D volumetric estimates.

\section{Experimental Setup}

Two phantom setups were used. A constant flow setup for validation (setup 1) and a tissue-mimicking phantom with pulsating flow (setup 2). Setup 1 was a rubber tube with a radius $(\mathrm{R})$ of $6 \mathrm{~mm}$ submerged in water and blood mimicking fluid was flowing inside the tube driven by a pump. A MAG 1100 flow meter (Danfoss, Hasselager, Denmark) was attached to measure the volume flow rate $\mathrm{Q}$, and determine the reference flow profile [7]. Assuming parabolic flow and a beam-to-flow angle of 90 degrees, the true center profile is:

$$
\begin{aligned}
v_{(\phi)}(r) & =\{v(r) \cdot \cos (\phi), v(r) \cdot \sin (\phi), 0\}, \\
v(r) & =v_{0}\left(1-\frac{r^{2}}{R^{2}}\right) .
\end{aligned}
$$

Here $v_{0}$ is the peak velocity, $R$ the radius of the vessel, and $\phi$ is rotation in the $x y$ plane (around $z$-axis). Validation of the profiles was performed using the bias $(\tilde{B})$ and standard deviation $(\sigma)$, against the true profile. $(\tilde{B})$ and $(\sigma)$ was calculated as in [19]. In total, 16 pairs of velocity estimates were average 

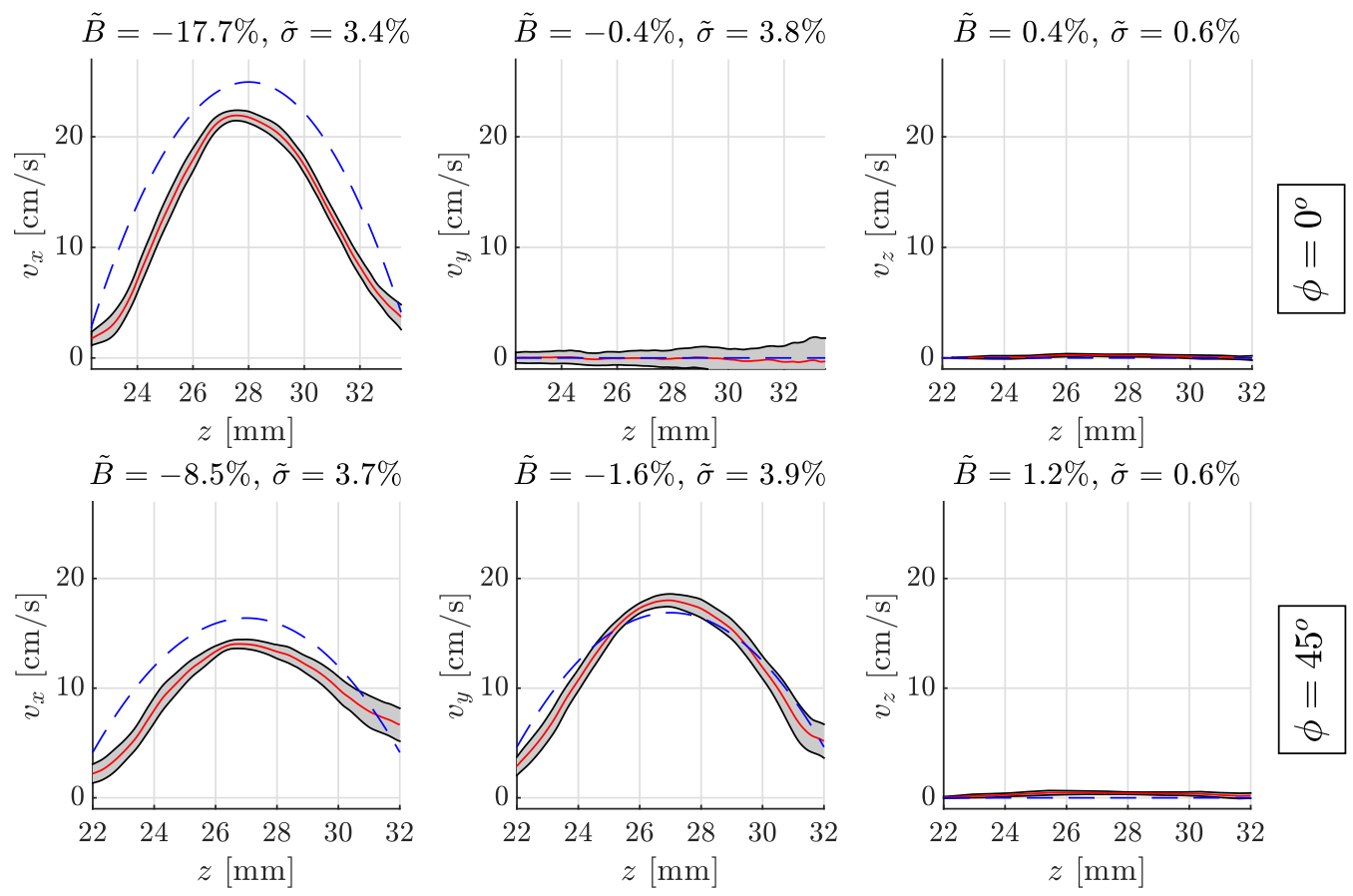

Fig. 2. Parabolic flow profiles, measured on a constant flow rig (setup 1) with $v_{\text {peak }}=0.25 \mathrm{~m} / \mathrm{s}$. In total 10 estimates were averaged to reveal a single profile. The estimated profile is shown in red, the shaded gray area show plus minus one standard deviation, and the dashed blue line is the true profile. The top panel has a rotation of $0^{\circ}$ around the $z$-axis. Bottom panel a rotation of $45^{\circ}$.

to reveal a single profile, and in total 10 profiles were used in the validation. The peak velocity was $25 \mathrm{~cm} / \mathrm{s}$. The RC probe was fixated allowing precise calibration of $\phi$. Two settings of $\phi$ were used, $0^{\circ}$ and $45^{\circ}$, to introduce velocities in both $x$ and $y$-direction.

Setup 2 consisted of a phantom made with tissue-mimicking material with a straight vessel in the center [20], [21]. The probe was positioned above the vessel with a transducer holder, keeping the probe steady during acquisition. A closedloop flow system (CompuFlow 1000, Shelley Medical Imaging Technologies, Toronto, ON, Canada) was used to pump blood mimicking fluid inside the vessel. The pump delivered pulsating flow with a period of $0.84 \mathrm{~s}$ and a peak volume flow of $10.0 \mathrm{~mL} / \mathrm{s}$, mimicking a carotid flow profile. 10 pairs of velocity estimates were averaged to reveal a single profile to avoid too high a smoothing in the temporal domain. In total 800 frames were acquired, the visualized flow and B-mode is a single frame from the series.

The penetration was estimated over 20 frames using a speckle phantom (Dansk Fantom Service, model 571) with an attenuation of $0.5 \mathrm{~dB} /[\mathrm{cm} \cdot \mathrm{MHz}]$. The penetration depth was estimated as where the signal-to-noise ratio (SNR) crossed 0.

\section{RESUlTS}

In Fig. 2 the results from setup 1 is shown. The center profile was extracted and compared to the true profile from (3). The profiles of all three components $\left(v_{x}, v_{y}, v_{z}\right)$ are visualized. $f_{\text {prf }}$ was set at $2 \mathrm{kHz}$ to limit reverberations in the water chamber. Parabolic profiles are seen for $v_{x}$ for both settings of $\phi$, and $v_{y}$ for $\phi=45^{\circ}$ as expected. They are visually comparable to the

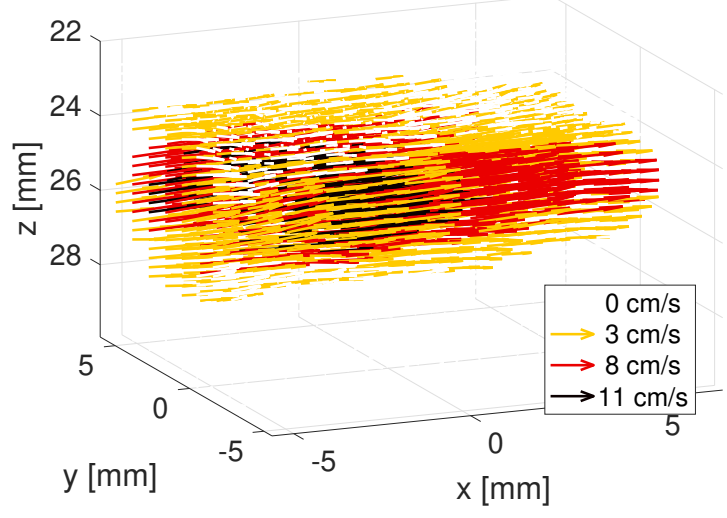

Fig. 3. Shows a single velocity estimate volumetric frame. Here colors shows different magnitude and velocity direction are shown with the arrows.

true profile. The largest bias was $-17.7 \%$, in the case of the highest peak velocity. The flow profiles had relative standard deviations $(\sigma)$ of 3 to $4 \%$ for $v_{x}$ and $v_{y}$ in both cases of $\phi$.

The volumetric velocity estimates of setup 2 are shown in Fig. 3, where flow in 3-D is visualized with arrows showing the direction and color the magnitude. The B-mode planes are shown in Fig 4. The two planes pass through the center of the vessel and are orthogonal to each other. These can be selected from anywhere in the volume. Setting $f_{p r f}$ to $10 \mathrm{kHz}$ can provide a B-mode volume rate above $125 \mathrm{~Hz}$. Penetration was measured to $14 \mathrm{~cm}$ for both the flow sequence and B-mode. 

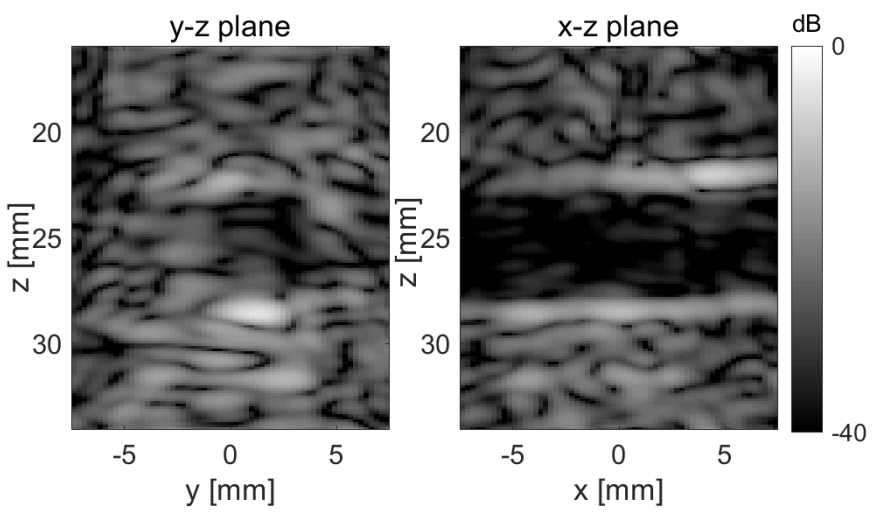

Fig. 4. Two B-mode planes are visualized with a dynamic range of $40 \mathrm{~dB}$, from setup 2 . These can be selected in the entire volume.

\section{Discussion AND CONCLUSION}

The center profiles showed a high precision, i.e., low $\sigma$, but a higher bias was seen. Rotating the transducer reduces the bias for $v_{x}$, without increasing the bias for $v_{y}$. The flow is then present in both components $\left(v_{x}, v_{y}\right)$ instead of only in $x$. The effect is seen when comparing the top panel to the bottom panel in Fig 2.

Using this RC array the number of channels is reduced by a factor of 16 compared to the $32 \times 32$ fully populated array. The demands for the system are therefore reduced by a factor of 16 in terms of data handling, storage, and processing. The larger surface size provides a penetration depth of $14 \mathrm{~cm}$. This provides flexibility in application, as the large penetration depth could be traded for a higher center frequency.

Likewise, the interleaved sequence allows more flexibility for $f_{p r f}$ to be adapted. The results demonstrate that fully volumetric vector flow imaging is achievable in 3-D with high volume rate. The use of only 62 channels, and this interleaved sequence allows it to be implemented on current scanner hardware.

\section{Acknowledgement}

This work was financially supported by grant 7050-00004B from Innovation Fund Denmark, and from BK Medical, Herlev, Denmark.

\section{REFERENCES}

[1] C. E. Morton and G. R. Lockwood, "Theoretical assessment of a crossed electrode 2-D array for 3-D imaging," in Proc. IEEE Ultrason. Symp., pp. 968-971, 2003.

[2] J. T. Yen, C. H. Seo, S. I. Awad, and J. S. Jeong, "A dual-layer transducer array for 3-D rectilinear imaging," IEEE Trans. Ultrason., Ferroelec., Freq. Contr., vol. 56, no. 1, pp. 204-212, 2009.

[3] A. Sampaleanu, P. Zhang, A. Kshirsagar, W. Moussa, and R. Zemp, "Top-orthogonal-to-bottom-electrode (TOBE) CMUT arrays for 3-D ultrasound imaging.," IEEE Trans. Ultrason., Ferroelec., Freq. Contr., vol. 61, no. 2, pp. 266-276, 2014.

[4] T. L. Christiansen, M. F. Rasmussen, J. P. Bagge, L. N. Moesner, J. A. Jensen, and E. V. Thomsen, "3-D imaging using row-column-addressed arrays with integrated apodization - part II: Transducer fabrication and experimental results," IEEE Trans. Ultrason., Ferroelec., Freq. Contr., vol. 62, no. 5, pp. 959-971, 2015.
[5] M. F. Rasmussen, T. L. Christiansen, E. V. Thomsen, and J. A. Jensen, "3-D imaging using row-column-addressed arrays with integrated apodization - Part I: Apodization design and line element beamforming," IEEE Trans. Ultrason., Ferroelec., Freq. Contr., vol. 62, no. 5, pp. 947-958, 2015.

[6] S. W. Smith, H. G. Pavy, and O. T. von Ramm, "High speed ultrasound volumetric imaging system - Part I: Transducer design and beam steering," IEEE Trans. Ultrason., Ferroelec., Freq. Contr., vol. 38, pp. 100-108, 1991.

[7] S. Holbek, T. L. Christiansen, M. B. Stuart, C. Beers, E. V. Thomsen, and J. A. Jensen, "3-D vector flow estimation with row-column addressed arrays," IEEE Trans. Ultrason., Ferroelec., Freq. Contr., vol. 63, no. 11, pp. 1799-1814, 2016.

[8] J. A. Jensen and P. Munk, "A new method for estimation of velocity vectors," IEEE Trans. Ultrason., Ferroelec., Freq. Contr., vol. 45, no. 3, pp. 837-851, 1998.

[9] S. Holbek, K. H. Lindskov, H. Bouzari, C. Ewertsen, M. B. Stuart, C. Thomsen, M. B. Nielsen, and J. A. Jensen, "Common carotid artery flow measured by 3-D ultrasonic VFI and validated with MRI," Ultrasound Med. Biol., vol. 43, no. 10, pp. 2213-2220, 2017.

[10] J. Sauvage, M. Flesch, G. Ferin, A. Nguyen-Dinh, J. Poree, M. Tanter, M. Pernot, and T. Deffieux, "A large aperture row column addressed probe for in vivo 4d ultrafast doppler ultrasound imaging," Phys. Med. Biol., vol. 63, pp. 1-12, 2018.

[11] J. A. Jensen and S. I. Nikolov, "Directional synthetic aperture flow imaging," IEEE Trans. Ultrason., Ferroelec., Freq. Contr., vol. 51, pp. 1107-1118, 2004.

[12] J. A. Jensen, "Estimation of high velocities in synthetic aperture imaging: I: Theory," IEEE Trans. Ultrason., Ferroelec., Freq. Contr., vol. 66, no. 6, pp. 1024-1031, 2019.

[13] J. A. Jensen, "Estimation of high velocities in synthetic aperture imaging: II: Experimental investigation," IEEE Trans. Ultrason., Ferroelec., Freq. Contr., vol. 66, no. 6, pp. 1032-1038, 2019.

[14] M. Engholm, H. Bouzari, T. L. Christiansen, C. Beers, J. P. Bagge, L. N. Moesner, S. E. Diederichsen, M. B. Stuart, J. A. Jensen, and E. V. Thomsen, "Probe development of CMUT and PZT row-columnaddressed 2-D arrays," Sens. Actuators A: Phys., vol. 273, pp. 121-133, 2018.

[15] J. A. Jensen, H. Holten-Lund, R. T. Nilsson, M. Hansen, U. D. Larsen, R. P. Domsten, B. G. Tomov, M. B. Stuart, S. I. Nikolov, M. J. Pihl, Y. Du, J. H. Rasmussen, and M. F. Rasmussen, "SARUS: A synthetic aperture real-time ultrasound system," IEEE Trans. Ultrason., Ferroelec., Freq. Contr., vol. 60, no. 9, pp. 1838-1852, 2013.

[16] H. Bouzari, M. Engholm, S. I. Nikolov, M. B. Stuart, E. V. Thomsen, and J. A. Jensen, "Imaging performance for two row-column arrays," IEEE Trans. Ultrason., Ferroelec., Freq. Contr., vol. 66, no. 7, pp. 1209-1221, 2019.

[17] M. B. Stuart, M. Schou, and J. A. Jensen, "Row-column beamforming with dynamic apodizations on a GPU," in Proc. SPIE Med. Imag., pp. 17, 2019. Paper number 10955-20.

[18] J. A. Jensen, "Directional transverse oscillation vector flow estimation," IEEE Trans. Ultrason., Ferroelec., Freq. Contr., vol. 64, no. 8, pp. 11941204, 2017.

[19] M. J. Pihl, J. Marcher, and J. A. Jensen, "Phased-array vector velocity estimation using transverse oscillations," IEEE Trans. Ultrason., Ferroelec., Freq. Contr., vol. 59, no. 12, pp. 2662-2675, 2012.

[20] J. Jensen, C. A. V. Hoyos, M. S. Traberg, J. B. Olesen, B. G. Tomov, R. Moshavegh, S. Holbek, M. B. Stuart, C. Ewertsen, K. L. Hansen, C. E. Thomsen, M. B. Nielsen, and J. A. Jensen, "Accuracy and precision of a plane wave vector flow imaging method in the healthy carotid artery," Ultrasound Med. Biol., vol. 44, no. 8, pp. 1727-1741, 2018.

[21] J. B. Olesen, C. A. Villagómez Hoyos, N. D. Møller, C. Ewertsen, K. L. Hansen, M. B. Nielsen, B. Bech, L. Lönn, M. S. Traberg, and J. A. Jensen, "Non-invasive estimation of pressure changes using 2-D vector velocity ultrasound: An experimental study with in-vivo examples," IEEE Trans. Ultrason., Ferroelec., Freq. Contr, vol. 65, no. 5, pp. 709719, 2018. 